\title{
Antropologia das Emoções: retomando concepções e consolidando campos
}

REZENDE, Claudia Barcellos e COELHO, Maria Cláudia.

Antropologia das Emoçóes.

Rio de Janeiro: Editora Fundação Getúlio Vargas.

Série Sociedade e Cultura, 2010, 136 p.

I Rosamaria Carneiro I

1 Professora adjunta de Saúde Coletiva/Ciências Sociais, Universidade de Brasília (FCE-UnB). Endereço eletrônico: rosacarneiro@unb.br

... o individuo, ao falar do que sente, comunica-se consigo mesmo através dos outros, compreendendo, por meio desta expressão, aquilo que sente (p.62)

O livro de Claudia Barcellos Rezende e de Maria Cláudia Coelho tem início com uma "fábula antropológica" vivida por Laura Bohannan: em um dia chuvoso de sua pesquisa de campo, ao compartilhar Hamlet com uma tribo africana, percebe como "os sentimentos são tributários das relações sociais e do contexto cultural em que emergem" (p. 11). Naquele espaço, amor e ciúme eram compreendidos e experimentados de outras maneiras e, por isso, o clássico ocidental pouco logrou mobilizar os ouvintes da trama. Esse é o episódio que anuncia a base do argumento das autoras: o fazer antropologia das emoções é justamente colocar em xeque ideias essencialistas e universais que, muitas vezes, temos dos nossos sentimentos e dos sentimentos dos outros.

Nas palavras das autoras, essa, no entanto, não é uma tarefa recente, quando consideramos que autores como Emile Durkheim e Georg Simmel também se dispuseram a pensar as emoções de modo não naturalista e muito mais atrelado ao mundo social; assim como também, na antropologia, Radcliffe-Brown, Ruth Benedict e Marcel Mauss procuraram compreender as tramas das regras e as formas coletivas de expressão dos sentimentos, explorando sua função e comparando seus padrōes e/ou configuraçōes. Entretanto, é na década de 1970 e na antropologia norte-americana que as autoras percebem o grande impulso ao estudo dos comportamentos, aos conceitos de pessoa, de self e das emoções, 
quando a cultura passa a ser definida como uma "teia de significados" (GEERTZ, 1989). De acordo com suas palavras, essa teria a mola propulsora para que, na década de 1980, as emoções passassem a ser pensadas mediante um viés relativista e, mais recentemente, mediante uma leitura contextualista, que procura apontar não só para a pluralidade de expressões culturais das emoções entre grupos, mas também no interior de um mesmo grupo, à luz do debate sobre relações de poder e do que denominam de seu potencial "micropolítico".

Para Coelho e Rezende, a questão também foi pautada no Brasil, desde Gilberto Freire e Sérgio Buarque de Holanda, para depois perpassar, nos idos de 1980, os escritos de Roberto DaMatta, em sua famosa distinção entre a casa e a rua; de Gilberto Velho e Tania Salem, sobre o ethos das camadas médias cariocas psicanalizadas, e depois, de Luiz Fernando Duarte sobre as camadas populares, a partir da noção de pessoa do "nervoso". Em minha leitura, essa breve contextualização histórica do campo da antropologia das emoções, primeiro, ressalta que a temática não é recente e, em segundo lugar, nos ajuda a compreender a conformação do assunto nos anos de 1990, quando o fazer antropológico das emoções ganha fôlego, despertando o interesse por revistas temáticas, de grupos e linhas de pesquisa, bem como de congressos nacionais e internacionais, que passam a contar com grupos de trabalho circunscritos à sua reflexão.

O livro encontra-se organizado em quatro capítulos: os dois primeiros têm uma base mais teórica, problematizando a seara das emoções à luz, respectivamente, da articulação natureza/cultura e estrutura/agência, enquanto os dois últimos estão dedicados à tematização da interface sentimentos e "micropolítica" e à crítica da noção de emoção na sociedade moderna ocidental. Em razão de assim vir desenhado, tendo a considerar que, em que pese sustentar a não novidade do assunto, trata-se de um dos primeiros esforços de peso para a sistematização e legitimação desse campo de pesquisa, ainda pouco conhecido ou, infelizmente, desmerecido por alguns antropólogos e demais cientistas sociais, que tendem a tratar o campo, de modo pejorativo, sob a alcunha de "pós-moderno".

O primeiro capítulo, "Emoções: biológicas ou culturais?”, concentra-se na desconstrução da perspectiva etnopsicológica de que as emoções estão ancoradas ao psicobiológico do indivíduo e de que são constantes e universais em razão de virem fundamentadas na oposição corpo/mente ou sentimento/razão. Nessa grade de leitura, as emoções aparecem ligadas ao corpo, enquanto a razão, à mente. 
Assim, as primeiras teriam origem no corpo e seriam negativadas em relação à mente, dando ensejo, por exemplo, à repetida ideia de que as mulheres são mais emotivas e, portanto, irracionais e incapacitadas para a vida pública. No entanto, na acepção das autoras, a leitura das ciências sociais seria outra e bem diferente, a saber, a de bem apontar, por exemplo, para culturas em que as emoções são tidas em alta conta e, até mesmo, supervalorizadas (LUTZ, 1998). Em suas palavras, para a antropologia, "o modo como entendemos e vivenciamos o corpo é sempre mediado pelas formas de pensar cultural e historicamente construídas. Assim, torna-se difícil separar o que seria um fato biológico de um fato cultural” (p.29).

Dessa maneira, com o intuito de ressaltar como as ciências sociais têm contribuído para a desnaturalização das emoções, a partir da rememoração de uma gama de trabalhos teóricos, argumentam em prol das emoções como fenômenos incorporados, situados no corpo, mas sem que isso implique dizer que sejam naturais. Pedem muito mais a atenção para a necessidade do aprendizado de como, quando e por quem certas emoçôes são manifestadas ou têm espaço e sentido simbólico, atravessando, inclusive, trejeitos corporais e faciais. De igual modo, recorrem à noção de que os sentimentos somente são demonstrados na interação social e de que a linguagem tem papel fundamental em sua transmissão. Nesse sentido, rememoram que também coube às ciências sociais o questionamento do caráter instintivo das emoções, na medida em que tende a compreendê-las a partir do aprendizado social e não como algo da ordem do inato e do descontrolado. $\mathrm{Na}$ realidade, bebendo de autores como Nobert Elias, em seus estudos sobre a relevância do medo na eficácia do processo civilizador, advogam que também os sentimentos controlam e são controlados pela sociedade. Anunciam, assim, a importância de se pensar emoção a partir uma relação cultural e histórica, sem deixar de pautar o corpo e seu controle nesse processo.

No segundo capítulo, "Emoçôes: individuais ou sociais?", as linhas seguem a tão famosa questão ação/reprodução ou agência/estrutura, na tentativa de refletir sobre a possibilidade de estudos sócio-antropológicos dos sentimentos e na contramão das premissas de sua individualidade e interioridade. $\mathrm{Na}$ tentativa de sustentar a viabilidade de tais abordagens, retomam, uma vez mais, autores clássicos, como Georg Simmel e sua ideia de "forma-motivação", Emile Durkheim e a noção de "fato social", e Marcel Mauss, com a aposta nos "sentimentos como linguagem”, terminando o capítulo com uma sequência de exemplos etnográficos 
que ilustram a culturalidade das emoções. De acordo com Simmel, toda interação social teria uma forma e uma motivação; por isso, caberia à sociologia o estudo desse binômio fluido, aplicável também à dimensão afetiva e ao estudo da nãoestabilidade dessas formas sociais. Para Durkheim, o fato social, como sabemos, existiria fora das consciências individuais e teria força coercitiva, assim como as emoções, que também encontram espaço no referido conceito, em que pese o autor apartar a psicologia da sociologia. E por fim, para Mauss, o sentimento teria uma expressão social na medida em que são ritualizados e seriam também linguagem, através da qual o homem comunica suas emoções aos demais.

Em seguida, as autoras recorrem à análise da história de Romeu e Julieta, enquanto mito de origem do amor romântico moderno, desenvolvida por Viveiros de Castro e Benzaquem de Araujo (1977), a fim de recuperar o caráter histórico do sentimento "amor". Tecendo fios argumentativos a partir da leitura holista/individualista de Louis Dumont, trazem à tona como o amor tem sido experimentado a partir da modernidade, quando o ethos individualista conquista espaço no Ocidente e pares analíticos como amor/família, corpo/nome e almacoração/corpo tomam outro desenho, dando uma suposta maior liberdade ao homem, que, outrora, tinha sua noção de pessoa externamente determinada. Nesse jogo, a ideia parece ser ressaltar, a partir também da tensão tipicamente moderna apontada por Simmel, "entre saber-se igual e saber-se singular" (p. 58), como amar também pode ser historicamente determinado e os sentimentos precisam ser historicizados e culturalizados. Nesse esforço de pontuar o caráter social das emoções ou, ainda, que as "experiências emocionais são, a um só tempo, subjetivas e sociais” (p. 74), recorrem aos estudos da própria Maria Cláudia Coelho sobre o amor do fã que procura descolar-se da massa (p. 58); ao debate de DaMatta sobre a saudade enquanto sentimento que brinca com a temporalidade cronológica (p. 66) e, por último, à etnografia da própria Claudia Rezende sobre a amizade no Rio de Janeiro e em Londres, quando o privado e o público adquirem colorações distintas (p. 69).

No penúltimo capítulo, "A micropolítica das emoções", a discussão gira ao redor da capacidade de as emoçōes dramatizarem/alterarem/reforçarem a dimensão macrossocial em que as emoções foram situadas. Para tanto, recuperam as correntes teóricas das emoções, a saber, o essencialismo (as emoções teriam uma estrutura universal e natural, preexistindo ao social), o historicismo e/ou 
relativismo (as emoções seriam um constructo cultural e histórico, a serem lidas, por consequência, mediante um viés relativista) e, por último, o contextualismo (inspirado numa leitura focaultiana, considera que as emoções, a um só tempo, moldam e nomeiam o social, vindo, por isso, atravessadas por relações de poder, hierarquias e concepçôes de moralidade que desenham fronteiras entre grupos). Nessa esteira, procurando ressaltar o caráter micropolítico das emoções, as autoras recorrem à discussão do sentimento de "gratidão" de Simmel enquanto subordinação e mecanismo de coesão dos laços sociais diante da dádiva, para tematizar a troca de presentes entre patroas e empregadas domésticas cariocas. Coelho é a responsável pelo empreendimento investigativo recuperado nesse momento da obra. De sua pesquisa teria ficado a perspectiva de que as patroas esperam a gratidão das empregadas enquanto expressão de manutenção do laço de subordinação da última para com ela, enquanto as empregadas, ao demonstrarem ingratidão (como é o caso daquela que ganha um pacote de bolacha), contribuiriam para a ruptura da ordem, do esperado ou previsível, dando margem para a dimensão micropolítica das emoçôes, que tanto reatualizam como transformam a sociedade (p. 89).

Por fim, em "As emoções nas sociedades ocidentais modernas", Rezende e Coelho percorrem autores que tematizaram as emoções na sociedade moderna, pontuando a diferença entre sentir e expressar; entre o controle das emoções, a fase hedonista do prazer e a questão da autenticidade. Em um primeiro momento, Richard Sennet é o autor recuperado, a partir da noção de "declínio do homem público" e de que as emoções passam a ter espaço no doméstico, onde o que há de mais profundo pode despontar, enquanto no público caberiam o controle e o cultivo do socialmente predeterminado. Nas linhas das autoras, os "estranhos passaram a ser mais misteriosos e a vida pública mais incerta, contrastando então com o aconchego oferecido pela família” (p. 100). Há, como bem pontuam, uma preocupação detida em descobrir-se e, assim, uma supervalorização do mundo privado e advento do narcisismo. De outra parte, também partilha-se da ideia de que o sujeito deve ter um controle emotivo, internalizado e automatizado, ou, recorrendo a Elias, tanto a "racionalização" quanto a "psicologização" dos comportamentos, a contenção e a necessidade de ajuste da conduta em função dos outros e a partir do medo e da vergonha (p. 106). Dito de outro modo, "se a vida torna-se menos perigosa, torna-se também menos prazerosa e essa é uma das cicatrizes deixadas pelo processo civilizatório, na visão de Elias” (p. 108). 
Entretanto, paradoxalmente, para Coelho e Rezende, a sociedade moderna é também o espaço da busca pelo prazer e o consumo, como sugerem as interpretações de Duarte e Colin Campbell. E isso ainda se vê agregado ao debate sobre autenticidade, quando, ao analisarem as relações amorosas na esteira de Anthony Giddens e Zigmunt Bauman, Coelho e Rezende ressaltam que mesmo, no amor, busca-se a individualidade ou o projeto pessoal, a despeito de buscar-se, simultaneamente, segurança e "certeza" da contrapartida. Em razão disso, com o advento da modernidade, as relações amorosas também são pautadas pelo consumo. De um modo ou de outro, a busca parece ser, antes, pela satisfação pessoal e, assim, "a vivência das relações amorosas nesses moldes ilustra a articulação dos valores da autenticidade da expressão de si, do controle emotivo e da ênfase no prazer e na satisfação característicos das experiências emotivas nas sociedades ocidentais modernas" (p. 122).

Feito esse percurso por autores consagrados no campo da antropologia e da sociologia, no esforço da desnaturalização das emoções enquanto sentimentos universais e naturais, as autoras nos brindam, ao final da obra, com outra vivência do amor trágico, a partir de Lila Abu-Lughod. Mais do que apontar para o caráter estrutural e universal das emoções, esta sinaliza para a particularidade da expressão dos sentimentos - que podem até matar -, como acontecera com um casal de beduínos apaixonados, mas separados por questões políticas durante longos anos.

Essa passagem, assim todas as muitas outras apresentadas no livro, denota a importância da compreensão das emoções in loco, (des)naturalizadas e (des) internalizadas e, portanto, atravessadas pela história e pela possibilidade de transformação social. Dessa maneira, trata-se de uma obra extremamente rica em termos de exemplos etnográficos e da rentabilidade e importância da temática das emoções para a compreensão de visões de mundo pluralizadas.

Em razão disso, em minha leitura, torna-se um marco no interior da teoria antropológica, na medida em que sistematiza e adensa um campo de pesquisa, enumerando autores e etnografias dedicadas ao assunto; no entanto, mais do que isso, apresenta de que maneira as emoções atravessam outras searas de pesquisa e despontam, por consequência, como solo profícuo de problematização da pluralidade cultural, dos mecanismos de controle social e das artes do viver. 


\section{Os vários mundos da saúde}

BASTOS, F. I.

\section{Saúde em Questáo.}

Rio de Janeiro: Claro Enigma / Fiocruz, 2012. 110 p.

I ${ }^{1}$ Claudia Cristina de Aguiar Pereira, 2 Carla Jorge Machado |

${ }^{1}$ Pesquisadora da Escola Nacional de Saúde Pública (ENSP/Fiocruz). Endereço eletrônico: pereirac.claudia@gmail.com

${ }^{2}$ Professora da Faculdade de Medicina da Universidade Federal de Minas Gerais (UFMG). Endereço eletrônico: carlajmachado@gmail.com

Publicado em 2011, o livro Saúde em Questão, editado pela Claro Enigma em parceria com a Editora Fiocruz, faz parte da nova coleção de ciências da Fundação Oswaldo Cruz, que já conta com um volume anterior: Biodiversidade em questão. O autor da obra, Francisco Inácio Bastos, também publicou mais de 200 artigos em periódicos, além de outros livros e capítulos de livros. Em Saúde em questão, o escritor aborda áreas correlacionadas, mas distintas, com desenvoltura. Através de uma exposição clara, o pesquisador estabelece com leveza os parâmetros para que se compreendam a vida e a saúde.

O livro se apresenta em sete capítulos, além de duas seções adicionais. Após explicitar a necessidade de conceituar a saúde e a vida, no primeiro capítulo, percorre um caminho lógico do que é "muito pequeno" em vista do ser humano (átomos e moléculas) para o "muito maior" (o planeta Terra, do ponto de vista do indivíduo), dos capítulos segundo ao sexto. O capítulo sétimo, didaticamente, retoma a questão inicial: "Afinal, o que é a saúde?” As duas últimas seçôes do livro (Sugestôes de atividades e Sugestôes de leitura) convidam o leitor a perceber, em primeiro lugar, as diversas dimensōes da vida e da saúde de forma prática. Em segundo lugar, aprofundar-se em temas tratados no livro por meio de outras obras.

O primeiro capítulo ("O que é a saúde”) reflete sobre o que é a vida e sobre a falta de consenso em defini-la, exemplificando esta falta de unanimidade por meio dos debates que existem sobre o que é "vida natural" e "vida artificial". 
O autor faz uma anologia desta dificuldade de definição com a dificuldade em se definir o que é a saúde, dizendo que definir a saúde pelo seu oposto, ou seja, ausência de doença, embora tentador, é algo circular e incompleto. É como definir um gato por não ser um cachorro ou como dizer que alguém baleado não está saudável, ainda que este evento não caracterize doença. Finalmente, o escritor comenta sobre a definição de saúde como o "silêncio dos órgãos", também problemática, proposta no século XIX. Essa definição é contrastada pelo "silêncio" do sistema imunológico quando um indivíduo é infectado pelo vírus HIV, por exemplo. Nesta situação, o "silêncio" é uma ausência de expressão clínica de uma batalha travada entre o vírus e as células de defesa infectadas, caracterizando, assim, uma expressão (silenciosa) da doença. O capítulo trata ainda da definição da Organização Mundial da Saúde - "saúde como completo bem-estar" - inaplicável ao mundo real. Apesar dos contrastes apresentados, o leitor não se sente frustrado, pois o autor faz uma analogia do amor com a saúde: difícil de definir, mas fácil de sentir.

A partir das ideias propostas no capítulo primeiro, o segundo ("O mundo do muito pequeno") aborda a composição do que existe no mundo - átomos e moléculas -, buscando entender por que o "muito pequeno", embora não diga respeito à vida e à saúde (o autor problematiza o tema), interfere na constituição do que é o nosso "eu". Os elementos são importantes porque não conseguimos sintetizá-los. Cita os exemplos dos oligoelementos, destacando o papel do zinco e do flúor. Assim, Bastos consegue traduzir um tema complexo em algo muito próximo do cotidiano do leitor, tais como os complexos vitamínicos.

Em sequência lógica, o terceiro capítulo cresce em dimensão (" $O$ mundo do pequeno”). Após explicar o que é homeostase, ATP, catálise e substratos e o ácido lático (chamando atenção para atividade física após um período de inatividade), os conceitos fluem bastante bem e é aí que se começa a entender o porquê das alergias, da Aids e porquê, se há indivíduos vivos, é devido ao sistema imunológico ter permitido. Ainda neste capítulo, o autor afirma que genoma não é algo vivo e sim um roteiro, que orienta as células, traçando um paralelo entre uma planta de arquitetura e uma construção. Explicita que, se o código genético de um alimento é modificado (os transgênicos), o organismo vivo pode não "entender" a nova mensagem e surgirão as alergias. Sem fazer alarde, mas deixando claras 
as implicações da engenharia genética, Bastos afirma que "é preciso ter alguma paciência com os transgênicos".

"Do meu e do seu tamanho" é o capítulo seguinte e trata do que está ao nosso alcance ou ao nosso plano de visão, como os exames para diagnóstico, as doenças transmissíveis e infecciosas e sua propagação, os surtos epidemiológicos e as doenças transmitidas por alimentos contaminados. O que há de inovador neste capítulo é a abordagem que se inicia no indivíduo e no seu significado - indivisível - e se alastra pelo conceito de rede social. Rede social, na saúde, atua permitindo a propagação de doenças e hábitos - tanto local quanto global. Os exemplos de disseminação que autor aborda são o vírus da Aids, a obesidade e a criminalidade.

Se no capítulo quarto a ideia eram as pessoas perto de nós, atuando em nossas vidas por meio de contatos diretos, ou simplesmente compartilhando vetores ou hábitos comuns, o capítulo seguinte aborda o que é a Saúde Pública, ou seja, o que é "maior que eu". As passagens são sempre pautadas pelas definições (o que é saúde pública, prevalência e estigma, por exemplo). Bem elaborada é a ideia do que (não) é o racismo e, finalmente, do que são o estigma social e a discriminação. O capítulo é inquietante e o autor deixa claro: "as vítimas de discriminação se sentem sós, tristes e desmotivadas". E isso afeta a saúde.

O capítulo sexto trata do planeta Terra, e de temas como fotossíntese, raios ultravioletas, câncer de pele, raquitismo, avançando em questôes atuais e preocupantes, como o buraco na camada de ozônio e o aquecimento global. Enfim, refere-se a algo "bem maior do que eu". Bastos cita desastres ecológicos e comenta, sem grande assombro e sem assustar o leitor (ele não se considera um pessimista), os efeitos de curto e longo prazo na saúde das pessoas. Segundo o autor: "estamos no fim das contas forçando a velha Terra a nos mandar mais cedo para o vestiário".

"Afinal, o que é saúde" é o título do sétimo capítulo, que vem somar os elementos trazidos nos capítulos anteriores, levando o leitor não a uma definição estanque, mas ao seu próprio entendimento do que é saúde. O que não é difícil, pois tudo o que é necessário para esta concepção ficou bem explicado ao longo dos capítulos anteriores. A ideia de que a saúde é uma construção harmônica e organizada emerge naturalmente. 
Ao final da leitura, percebe-se que o autor seguiu uma linha de raciocínio e ordenamento lógico criativos, abordando temas que vão desde as partículas subatômicas até as estrelas. Ao percorrer os mundos que variam do muito pequeno ao muito grande, Bastos faz um passeio pela Inglaterra da Revolução Industrial, o porto de Minamata, no Japão, poluído por causa do mercúrio, até o espaço sideral, registrando os efeitos da ausência de gravidade no corpo dos astronautas. Em uma abordagem ampla, chegou até mesmo diferenciar símios (apes, em inglês) de macacos (monkeys). Por outro lado, em alguns pontos, o autor mostrou-se repetitivo, como no caso das bombas americanas lançadas sobre Hiroshima e Nagasaki.

Necessário registrar ainda que o escritor deixou de mencionar alguns nomes importantes da História, principalmente no quarto capítulo, onde trata das infecções. Por exemplo: poderia ter informado ao leitor sobre o papel de pessoas como a enfermeira britânica Florence Nightingale, que durante a guerra da Crimeia, constatou que a falta de higiene no tratamento de feridos provocava doenças tão ou mais letais aos soldados que as próprias feridas, advocando, assim, mudanças que salvaram muitas vidas. Também esteve ausente a contribuição pioneira do médico Ignaz Phillip Semmelweiss, que observou a transmissão de doenças nos hospitais causada pela falta de esterilização dos equipamentos cirúrgicos e de assepsia pelos médicos, por não seguirem atos simples como desinfetar as mãos.

A obra seria enriquecida se, nesse mesmo capítulo, houvesse menção da batalha de anos entre os defensores de que a transmissão de doenças acontecia através de micróbios, como John Snow, contra os que defendiam a teoria dos miasmas, dentre os quais estava Edwin Chadwick, e que levou muito tempo para ser refutada. Os miasmistas defendiam que doenças como a cólera eram causadas por mau cheiro ou miasma. Tal crença está relacionada a milhares de mortes por cólera em Londres e Paris, afetando até mesmo o Rio de Janeiro nos tempos do sanitarista Oswaldo Cruz.

A descoberta dos antibióticos, ocorrida por acaso, como a penicilina, pelo médico escocês Alexander Fleming, é também uma ausência sentida na obra. Outra ausência decorre do fato de o autor, embora tenha feito observaçôes 
importantes sobre elementos como o zinco e flúor no segundo capítulo, não se ter dedicado ao sódio (cloreto de sódio), cujo papel no funcionamento do organismo é imprescindível.

Apesar de algumas lacunas, até mesmo esperadas pela abrangência de temas contemplados na obra, o livro pode e deve ser utilizado como material auxiliar aos estudantes do ensino médio, como o próprio autor sugere. Contudo, o papel da obra é muito maior. É um convite a todos, não apenas estudantes, a atualizarem seus conceitos de vida e de saúde por intermédio de uma perspectiva integrada e sequencial, que vai do muito pequeno ao muito grande, com notável fluidez, tornando a leitura leve e agradável. ${ }^{1}$

\section{Nota}

${ }^{1}$ As autoras participaram igualmente de todas as etapas de elaboração desta resenha. 